\title{
"A importância do ato de ler": amorosidade, afetividade e diálogo como prática alfabetizadora
}

"The importance of the act of reading": loveliness, affectivity and dialog as a literacy practice

\section{Alda Siqueira Lage de Oliveira siqueiralda@gmail.com \\ Mestre em Educação - Educação, \\ Desigualdades sociais e Políticas públicas - PUC Rio}

\section{Deisilucy de Aragão Fernandes Sequeirra deise.sequeira@gmail.com} Mestranda em Políticas, História e Cultura em Educação - UNIRIO (bolsista CAPES)

\section{Tatiane Rodrigues Souza tatiane.loretos@gmail.com \\ Mestre em Educação - Educação, Desigualdades sociais e Políticas públicas - PUC Rio}

\section{Resumo}

Este trabalho apresenta a contribuição de Paulo Freire para as políticas de alfabetização. Problematiza a proposta da Base Nacional Comum Curricular, sua concepção curricular e dialoga com o pensamento de Paulo Freire e com as reflexões de professores de duas diferentes redes de ensino municipais do Estado do Rio de Janeiro. Numa análise de conteúdo desse material, observamos que os docentes estão comprometidos com uma prática de liberdade.

Palavras-chave: Paulo Freire; concepção de alfabetização; BNCC; prática de liberdade; percepções dos docentes.

\begin{abstract}
This paper presents Paulo Freire's contribution to literacy policies. It approaches the National Common Core Curriculum proposal, its curricula design, dialogues with Paulo Freire's ideas and the reflections of teachers from the public school system of two different cities in the state of Rio de Janeiro. With a content analysis of the material, we were able to notice that the educators were committed to a practice of freedom.
\end{abstract}

Keywords: Paulo Freire; conceptions of literacy; National Common Core Curriculum; practice of freedom; teachers' perceptions. 


\section{Introdução}

Este artigo propõe discutir contribuições de Paulo Freire para a alfabetização enquanto exercício pleno da cidadania. Desde a federalização encetada na Proclamação da República que as práticas de leitura e escrita vem sendo perseguidas como um projeto de desenvolvimento e modernização do Estado republicano brasileiro. Fato é que o processo de escolarização da população, embora garantido pelo recente "direito à aprendizagem", não é um objetivo universalizado. O projeto de alfabetização idealizado por Freire insere-se nas lacunas provenientes dos dados alarmantes de analfabetos desde os anos 1990.

Este estudo está dividido em cinco seções, incluindo esta introdução. Inicialmente, aborda-se a recente política curricular, a Base Nacional Comum Curricular (BNCC), que se caracteriza por uniformizar os conteúdos curriculares. A seção posterior trata da concepção da alfabetização na BNCC. Esta proposta política curricular resgata os métodos sintéticos, com ênfase no método fônico. Num contraponto, são expostos na seção seguinte os ideais freirianos para uma alfabetização nacional. Distanciando-se da BNCC, Paulo Freire enuncia uma prática alfabetizadora que ultrapassa as questões dos métodos de alfabetização. A partir da triangulação entre as conversas com as professoras das redes de ensino municipais do Estado do Rio de Janeiro, o pensamento de Paulo Freire e as concepções de alfabetização identificadas na nova BNCC é possível destacar as contribuições do legado de Paulo Freire na práxis docente da alfabetização.

\section{Breve Histórico da BNCC}

A BNCC é uma política curricular que busca a homogeneização de conteúdos prescritivos, oferecendo uma visão muito limitadora. Tal entendimento traz em seu cerne a desigualdade de conhecimento. Importante ressaltar que o currículo não é um corpo neutro; ele está relacionado intrinsicamente às estruturas econômicas e sociais. Para isso, seria importante traçarmos um breve histórico da BNCC que contextualize o momento pelo qual passou o desenho da política.

Cabe ressaltar que com a redemocratização do país, em 1988, o Brasil passou a contar com um robusto arcabouço jurídico que estabeleceu, na Constituição Federal, a educação como um direito público subjetivo (Duarte, 2004), o que obriga o Estado a elaborar políticas públicas que visam garantir esse direito. Também, a Lei de Diretrizes e Bases da Educação (LDB N ${ }^{\circ}$ 9.394, de 20 de dezembro de 1996), determinou que os currículos da Educação Básica tivessem uma base nacional comum; logo após, foram criados os Parâmetros Curriculares Nacionais 
(Brasil, 1997). Anos mais tarde, em 2013, o governo federal lançou as Diretrizes Curriculares Nacionais (Brasil, 2013). O Plano Nacional de Educação (PNE - Lei N 13.005, de 25 de junho de 2014) vem reiterar a necessidade de uma base nacional (Brasil, 2014). A partir de todo esse regramento jurídico brasileiro, e inserida num contexto de busca pela construção de um Sistema Nacional de Educação, foi instituído em 2015 uma Comissão de Especialistas, composta por 116 membros das várias áreas de conhecimento e seus respectivos componentes curriculares para a elaboração da Proposta da Base Nacional Comum Curricular. Esta proposta se consolidou como a primeira versão da BNCC, entre outubro de 2015 e março de 2016. Diante do contexto político pelo qual o Brasil vivia naquele momento, o MEC lançou a segunda versão da BNCC.

Com as mudanças ocorridas no governo, em 2016, especialistas foram afastados e outro grupo assumiu o comando para a elaboração da terceira versão do documento, entregue ao CNE em abril de 2017. Essa terceira versão foi alvo de muitas críticas. A principal crítica recaiu sobre a ruptura da transparência e do processo democrático de construção da BNCC, se contrapondo, também às concepções de educação que, até a versão anterior, vinham conduzindo a elaboração da BNCC. Essa versão apresenta uma nova proposta de competências gerais a serem desenvolvidas entre os estudantes em todas as etapas da Educação Básica. Tal mudança se justifica com base nas reformas curriculares das últimas décadas, que foram empreendidas em diversos países e também nas avaliações educacionais em larga escala nacional e internacional, cujo foco era conceber concepções de escola, de conhecimento escolar e de formulação de currículos homogeneizantes.

\section{O que diz a BNCC com relação a Alfabetização}

Considerando os modelos prescritivos de alfabetização tradicionalmente impetrados no Brasil, o quadro das perspectivas teóricas que movem os documentos oficiais está, cada vez mais, empenhado no descolamento entre as perspectivas teóricas válidas e as condições socioculturais de nossas crianças, especialmente pelo indicativo das propostas que não dialogam com as realidades plurais das escolas, da formação docente e dos condicionantes estruturais profundamente desiguais no país.

O capítulo 4 da BNCC apresenta no tópico 1 - Área de Linguagens - diversos subtópicos ou subseções, sendo que deles, nos interessamos pelo subtópico "4.1.1.1 Língua Portuguesa no Ensino Fundamental - Anos Iniciais: práticas de linguagem, objetos de conhecimento e habilidades", que aborda o currículo referente ao ciclo de alfabetização, apresentando, em 
linhas gerais, as concepções que o fundamentam e, mais detalhadamente, as competências e habilidades que devem ser desenvolvidas.

Identifica-se no documento a afirmação de que o processo de alfabetização pode ser concretizado nos dois primeiros anos de alfabetização.

Embora, desde que nasce e na Educação Infantil, a criança esteja cercada e participe de diferentes práticas letradas, é nos anos iniciais $\left(1^{\circ}\right.$ e $2^{\circ}$ anos $)$ do Ensino Fundamental que se espera que ela se alfabetize. Isso significa que a alfabetização deve ser o foco da ação pedagógica. (Brasil, 2017, p. 89)

Pode-se observar vários fatores, dentre eles, a redução de 3 (três) para 2 (dois) anos da obrigatoriedade da alfabetização das crianças no Ensino Fundamental, uma vez que o Plano Nacional de Educação (PNE) previa que este processo pudesse acontecer ao longo dos 3 (três) primeiros anos de alfabetização (PNE, 2014-2024). Para Ferreiro e Teberosky (1985), é um equívoco definir o momento de iniciação e de finalização da alfabetização das crianças, uma vez que esta aprendizagem depende muito mais da qualidade e da quantidade dos estímulos e das ocasiões sociais de contato com a linguagem escrita do que com a maturidade da criança.

A BNCC parece resgatar as concepções de alfabetização dos Métodos Sintéticos, em especial, o método fônico. Isso aparece quando o documento afirma que

é preciso que os estudantes conheçam o alfabeto e a mecânica da escrita/leitura - processos que visam a que alguém (se) torne alfabetizado, ou seja, consiga "codificar e decodificar" os sons da língua (fonemas) em material gráfico (grafemas ou letras), o que envolve o desenvolvimento de uma consciência fonológica (dos fonemas do português do Brasil e de sua organização em segmentos sonoros maiores como sílabas e palavras) e o conhecimento do alfabeto do português do Brasil em seus vários formatos (letras imprensa e cursiva, maiúsculas e minúsculas), além do estabelecimento de relações grafofônicas entre esses dois sistemas de materialização da língua. (Brasil, 2017, p.89-90)

Como observamos no trecho acima, o alfabetizado é aquele que consegue "codificar e decodificar os sons da língua (fonemas) em material gráfico (grafemas ou letras)" (Brasil, 2017, p.90), recolocando na agenda curricular a dimensão mecanicista do processo de alfabetização. Embora o documento reconheça a diversidade linguística do país, tal aspecto parece não ser relevante no processo de alfabetização das crianças, uma vez que o foco está no desenvolvimento de habilidades de codificação e decodificação, denominadas de transcodificação linguística. 
Outro fator a ser considerado, conforme a BNCC, está em "garantir amplas oportunidades” (Brasil, 2017, p.55), como se essas fossem possíveis em todo território nacional, considerando que, em grande parte das escolas brasileiras o sucateamento das estruturas não permite essa amplitude de oportunidades. Isso porque muitas escolas não têm bibliotecas organizadas, salas de leitura apropriadas por ano e idade escolar, programas de alfabetização condizentes às realidades plurilinguísticas e dialetais das regionalidades, dentre outros aspectos que normatizam verticalmente a política oficial. Tudo como se essa "garantia ampla de oportunidades" fosse cabível a todas as realidades brasileiras.

Outra dimensão a ser mencionada é a que supostamente envolve a apropriação do sistema de escrita de modo articulado ao desenvolvimento de outras habilidades, tentando exaltar as 10 (dez) competências e habilidades previstas de forma pragmática na BNCC e que estão mais associadas aos parâmetros da pedagogia de competências. A pedagogia de competência é uma perspectiva tecnicista propulsionada no Brasil a partir da década de 1970, que favoreceu, em especial, os métodos de alfabetização regrados e prescritivamente seriados.

\section{Alfabetização para Paulo Freire}

Entre os anos 1946 e 1960, fixa-se o direito constitucional à educação, e, neste período em que é aprovada a primeira Lei de Diretrizes e Bases, são repensados órgãos importantes ao desenvolvimento educacional, científico e tecnológico do país. Nesse mesmo período, estava em debate a educação da população, considerando que ao final dos anos 1950 o Brasil mantinha uma taxa de quase $40 \%$ de analfabetos com idade superior a 15 anos, num mesmo contexto em que se debatia a modernização e o desenvolvimento industrial do país.

Os anos 1960 foram profundamente marcados pela ruptura do regime democrático. No entanto, foi um período que contou com grandes pensadores com atuação no governo e em instituições estatais. No rastro do desenvolvimento brasileiro, esses intelectuais influenciaram na construção de um plano de desenvolvimento nacionalista.

A educação dentro deste projeto político nacionalista-desenvolvimentista voltava-se a formar o sujeito como fator humano. Uma formação destinada, essencialmente, à classe trabalhadora, colocando-a não só como produtora, mas como detentora do processo produtivo e do produto desta produção. Uma “educação popular como meio de libertar o homem, mais do que, apenas, para ensiná-lo, torná-lo ‘doméstico"” (Brandão, 1981, p.17). A educação, seguindo os ideais nacionalistas, assume um lugar de destaque na valorização e na proteção das riquezas nacionais. 
Do mesmo modo, o pensar do processo de ensino consistia na construção de uma prática pedagógica que parte dos aspectos sociais, culturais, econômicos e históricos brasileiros, e que esteja de acordo com o território de origem do alfabetizando. Em termos de prática de alfabetização, numa clara referência aos métodos de alfabetização vigentes no país, o trabalho de Paulo Freire desloca-se da esgrima entre o método sintético e o método analítico (Mortatti, 2006).

Na trajetória da educação brasileira, Freire (1975) questiona o tipo de ensino mecânico que apenas reproduz o conhecimento e faz com que o sujeito apenas receba passivamente os saberes através da memorização, sem questionar e refletir sobre esse conhecimento. Freire denomina tal concepção de “(...) concepção ‘bancária’ da educação, em que a única margem de ação que se oferece aos educandos é a de receberem os depósitos (o conhecimento), guardá-los e arquivá-los" (Freire, 1975, p.66).

Assim, na perspectiva freiriana, a concepção de alfabetização assume um caráter filosófico, reflexivo e político, pois fundamenta-se numa concepção de educação emancipatória, possibilitando que o educando das camadas populares conheça a função social da língua e, no processo de aprendizagem, desenvolva a consciência crítica sobre suas realidades (Freire, 1975).

Freire também aponta que, ao longo da história, a educação escolar foi marcada por modos de produção curricular em série e padrões normatizadores no ensino e aprendizagem, tendo como finalidade formatar os indivíduos desde a infância para a passividade e o ajustamento dos corpos e mentes, produzindo um indivíduo passivo e alienado para atender as demandas do capital. Como ressalta Freire (1975), a educação bancária é pensada para formatar e silenciar a massa, ou seja, a classe trabalhadora, fazendo com esta não questione nem reflita sobre a desumanização que o capitalismo causa ao transformar o trabalhador em alienado.

Percebe-se que a educação, desde a modernidade, tem relações profundas com modelos de produção sob a égide do capital, que promoveu a seriação do conhecimento e estratificação administrativa da escola, resultando numa educação de massas. Nesse sentido, desde a revolução industrial, o capitalismo tem utilizado a educação escolar para domesticar o sujeito, selecionando e oferecendo um ensino pragmático, engessado e estanque, que não produz reflexão, questionamento e emancipação.

Por isso, Freire (1975) enfatiza que o ensino não é neutro, pois o currículo fundamentase na política social, cultural e econômica do capital. O currículo determina qual conhecimento o discente irá adquirir em cada etapa escolar, selecionando, assim, o que deve aprender para reproduzir os interesses da sociedade capitalista. 
Como aponta o autor:

Só assim a alfabetização cobra sentido. É a consequência de uma reflexão que o homem começa a fazer sobre sua própria capacidade de refletir. Sobre sua posição no mundo. Sobre o mundo mesmo. Sobre o seu trabalho. Sobre seu poder de transformar o mundo. Sobre o encontro das consciências. Reflexão sobre a própria alfabetização, que deixa assim de ser algo externo ao homem, para ser dele mesmo. Para sair de dentro de si, em relação com o mundo, como uma criação. Só assim nos parece válido o trabalho da alfabetização, em que a palavra seja compreendida pelo homem na sua justa significação: como uma forma de transformação do mundo. Só assim a alfabetização tem sentido. $\mathrm{Na}$ medida em que o homem, embora analfabeto, descobrindo a relatividade da ignorância e da sabedoria, retira um dos fundamentos para sua manipulação pelas falsas elites. Só assim a alfabetização tem sentido. (Freire,1975, p.142)

Assim, nesse movimento de que alfabetização não é uma ação estática e mecânica, derivando do pensamento de Freire (1981), pode-se afirmar que a aquisição da leitura e da escrita deve ser concebida com reflexão e conscientização e, assim, o processo de alfabetização deve iniciar pela discussão da palavra geradora, trazendo não apenas o significado da palavra “em si”, mas sua função social, cultural e política, para que assim o educando exerça a reflexão sobre essa palavra no contexto social.

Segundo Brandão, a aplicação do método Paulo Freire foi pensada metodologicamente em 5 etapas:

$\left.1^{\circ}\right)$ existem um ou mais círculos formados ou em formação; $2^{\circ}$ ) foi feito um primeiro momento do trabalho de pesquisa de descoberta do universo vocabular e/ou (hoje em dia mais e do que ou) do universo temático; $3^{\circ}$ ) todo o material da pesquisa feita dentro e fora da comunidade $4^{\circ}$ ) o instrumental do trabalho de alfabetização foi codificado, transformado em símbolos de uso no circulo de cultura: $5^{\circ}$ ) a equipe de trabalho e, sobretudo, os animadores de círculos de cultura, estão não só familiarizados com o método e o seu material especifico. (2006, p.40)

Com isso, conforme destacado pela autora, após a conscientização da palavra geradora, ocorre a correlação entre a palavra escrita e falada, para depois formar a decomposição das sílabas e suas junções, formando, em seguida, novas palavras até a produção de um texto significativo para o educando, desenvolvendo, assim, uma consciência crítica sobre a realidade (Freire, 1975). 


\section{Diálogos em Construção}

Nesta seção, abordaremos a importância do pensamento de Paulo Freire para a alfabetização através das narrativas das docentes entrevistadas em duas diferentes redes municipais. Importante ressaltar que a partir destas narrativas ficaram emergentes três categorias de análise que chamam atenção, sendo elas: a concepção de alfabetização, o método de alfabetização e o pensamento de Paulo Freire. Cabe dizer que, à vista da dissociação da concepção e dos métodos de alfabetização, se faz necessária essa junção, a fim de melhor esclarecimento do assunto. Assim, diante das reflexões feitas a partir das narrativas das docentes, surgiram alguns conceitos fundantes do pensamento de Paulo Freire, que contribuíram para a construção deste estudo.

Em nossa pesquisa, constata-se que, em sua maioria, o discente surge como o centro do ensino e da aprendizagem, bem no sentido freiriano de primeiro estabelecer o que é essencial ao ser humano. Apesar disso, essa centralidade parece estar relacionada com os aspectos cognitivos e com a capacidade de aprendizagem do aluno. No que tange à concepção de alfabetização, ganham relevo as interpretações voltadas às teorias, aos métodos, às técnicas e ao domínio do sistema alfabético, e menos as voltadas à alfabetização como um processo. Isso porque, para Freire (1983), a alfabetização não é um jogo de palavras; é a consciência reflexiva da cultura, a reconstrução crítica do mundo humano, a abertura de novos caminhos. A alfabetização, portanto, é toda a pedagogia: aprender a ler é aprender a dizer a sua palavra (Freire, 1983).

Percebe-se na fala da docente Azaleia: “(...) uma alfabetização através da pergunta, para que a gente possa sentir mais desejo de se relacionar com esse mundo da palavra e relacionando com o mundo de uma maneira mais enigmática e mágica". Esta docente utiliza, para alfabetizar as crianças, perguntas que despertam em sua prática alfabetizadora os questionamentos sobre o mundo e sobre si, aproximando-se do que Freire enfatiza: "quando entro em uma sala de aula devo estar sendo um ser aberto a indagações, à curiosidade, às perguntas dos alunos, as suas inibições, um ser crítico e inquiridor, inquieto" (1967, p.27).

O significado de concepção de alfabetização confunde-se com o de métodos de alfabetização. Como se de um lado estivessem os aspectos filosóficos da alfabetização e, de outro, a eficácia dos métodos de alfabetização e a intencionalidade baseada na evidência cognitiva do aluno. A alfabetização não pode ser reduzida a uma escolha entre conceitos e métodos (Soares, 2020 p.135), pois esta deve perpassar a apropriação crítica da própria cultura e da própria história do alfabetizando (Freire, 1990). Embora permaneça a crença de que a maior 
ênfase deve ser dada à "leitura técnica e as habilidades para a escrita", a "alfabetização deve ser situada dentro de uma teoria de produção cultural e encarada como parte integrante do modo pelo qual as pessoas produzem, transformam e reproduzem significado" (Freire, 1990 p.90). Na análise de Freire, a abordagem tradicional da alfabetização

ignora a inter-relação entre as estruturas sociopolíticas de uma sociedade e o ato de ler. A exclusão das dimensões social e política da prática da leitura dá origem a uma ideologia de reprodução cultural, aquela que encara os leitores como objetos. (1990, p.90)

Do mesmo modo, procede o aprendizado mecânico da habilidade de leitura sendo compreendida dentro de uma abordagem utilitarista. Para Freire, o processo de alfabetização deve problematizar o conflito de classe e as desigualdades. "Agir de outra maneira será negar aos alunos os direitos que estão no cerne da noção de uma alfabetização emancipadora" (Freire, 1990). As habilidades de leitura e escrita têm suas especificidades, mas não se "dicotomizam, ao contrário, se complementam" (Streck, 2010 p.223).

A prática alfabetizadora enquanto práxis, deve ser encarada como "a estreita relação que se estabelece entre um modo de interpretar a realidade e a vida e a consequente prática que decorre desta compreensão levando a uma ação transformadora" (Streck, 2010, p.325).

A práxis freiriana é representada na reflexão da docente Azaleia como

a possibilidade de deslocamento. Deslocamento das coisas, deslocamento de si mesmo, deslocamento com o outro, do mundo. Então, assim, aquilo que eu tento habitar é uma relação com essa infância. Que me ajude a pensar as coisas do mundo, uma delas é a leitura e a escrita do mundo. Que não é apenas da palavra, mas, dos sentidos que nos atravessam dos múltiplos sentidos, dos muitos sentidos que estão ainda no mundo e que a gente ainda não acessou, não abriu, que habita no invisível. (Depoimento pessoal)

Nesta categoria, a contribuição freiriana para este trabalho é a reflexão da educação como uma prática de liberdade, gerando, com isso, inéditos viáveis, cujo currículo e sua práxis respeitem de fato a cultura e a participação de todos na sua construção. Cabe dizer que, segundo Paulo Freire, o inédito viável é "uma palavra epistemologicamente empregada para expressar, com enorme carga afetiva, cognitiva, política, epistemológica, ética e ontológica, os projetos e os atos das possibilidades humanas" (Streck, 2010 p.223). Percebe-se que pode existir um diálogo entre currículo e cultura, principalmente na alfabetização, pois ao constatar a dimensão que a cultura pode tomar, é visível a promoção de uma dimensão humanista, integrada, de 
libertação e de humanização curricular. O diálogo é como um processo “(...) dialético problematizador. Ou seja, através do diálogo podemos olhar o mundo e a nossa existência em sociedade como processo, algo em construção, como realidade inacabada e em constante transformação" (Freire 2010, p.117). Esse mesmo movimento é identificado na narrativa da docente Azaleia, que destaca como

importante, nesse meu processo de trabalho com alfabetização, a pergunta. Aquela que se coloca em questão, coloca o outro em questão e coloca um monte de coisa em questão, no sentido de exame, de problematizar, olhar aquilo como se fosse da primeira vez, de uma maneira enigmática e curiosa. (Depoimento pessoal)

Assim, Streck ressalta que o sujeito se reconhece

ao interferir e transformar os elementos que estão à sua disposição na natureza e no mundo que o rodeia, produz cultura, expressa de diferentes modos e com diferentes linguagens, humanizando aquilo que toca, quer pertencendo a uma cultura letrada ou iletrada (2010, p.99).

Portanto, um currículo humanizado é formado pelo reconhecimento do homem como parte pertencente desse currículo. Nesse sentido, a prática da professora Hortência ilustra a criticidade no processo de alfabetização, como demonstra o texto a seguir:

eu tento pegar alguns princípios dele e fazer com que as crianças vejam sentido em aprender, a estudar, a estar na escola principalmente para ter um senso crítico e poder enxergar o mundo de uma maneira diferente, para eles poderem correr atrás dos direitos deles, não só os deveres e poder enxergar as coisas e cobrar dos governantes. Votar melhor até para poder cobrar, mas, enfim, para eles terem realmente um conhecimento, não só o "b com a" mas ele saber para que ele aprendeu o "b com a". (Depoimento pessoal)

A prática da docente dialoga com conceito de criticidade idealizado por Freire (2010), em que ele afirma que: "a criticidade é a capacidade do educando e do educador refletirem criticamente a realidade na qual estão inseridos, possibilitando a constatação, o conhecimento e a intervenção para transformá-la" (Freire, 2010, p.97).

O conceito de educação bancária, de Paulo Freire (1967), estabelece a prática de ensino em que o educador se coloca em posição superior, como o dono do saber, reproduzindo a sociedade opressora. Vemos também que a questão da alfabetização impõe conteúdos e métodos determinados, que ditam conhecimentos que todos devem possuir, sem respeitar as 
particularidades de cada indivíduo e sem entender que a educação não se constrói por meio de um saber pronto, que é transferido, mas sim na construção com os educandos de uma forma crítica e libertadora.

Assim, buscamos ver uma prática educativa em que o currículo possa se fundamentar numa relação horizontal entre educador e educandos, por meio do diálogo e mediada pelo mundo, possuindo práticas libertadoras e reflexivas. Isso se constata no exercício docente nas duas redes de ensino nos lócus dessas professoras. A professora Margarida afirma: "a concepção de postura pedagógica que acredito, independentemente de método, é que se tenha afetividade com o aluno, ou seja, afetá-lo de forma positiva para o aprendizado" (depoimento pessoal). O pensamento freiriano se mostra presente no sentimento e se confirma na fala da docente Azaleia: “eu acredito que a contribuição para minha prática hoje é uma relação amorosa - com o mundo, amorosa com o outro, amorosa comigo mesma" (depoimento pessoal).

Portanto, sabendo que o homem é um ser inacabado, se faz presente o entendimento de que um currículo pode ser construído a partir de variadas possibilidades de contextos educacionais, em que não existam contraposições, mas sim um processo contínuo, crítico e libertador, que possa desvelar as desigualdades, promovendo assim a emancipação dos discentes. A partir disso, Freire enfatiza a importância do diálogo enquanto interação das relações humanas, trazendo a educação de qualidade como produto dessa relação. Ele aponta também para a formação de uma educação voltada para uma prática de liberdade, cujo currículo seja emancipador e se volte para uma linguagem que dialogue com a práxis pedagógica.

\section{Algumas considerações}

Não é nossa pretensão esgotar neste artigo a reflexão sobre práticas alfabetizadoras à luz do pensamento de Paulo Freire, e sim abrir novas possibilidades de debate e reflexões sobre essa temática. Das conversas selecionadas para a construção deste artigo, observa-se que Paulo Freire é um intelectual conhecido de todas as docentes com que trabalhamos. E mesmo as que não estabeleceram uma relação mais próxima com as obras do autor demonstraram vivenciar uma prática freiriana oriunda da formação continuada, encontros e seminários. Destaca-se, nas narrativas docentes, que muitas práticas experienciadas no cotidiano escolar, mesmo sem serem reconhecidas, expressam e dialogam com o pensamento de Paulo Freire, como, por exemplo, quando o discente é colocado como centro do processo de aprendizagem dos conhecimentos. São as experiências que provocam na criança o questionamento, a reflexão, o diálogo; isso leva à emancipação. 
OLIVEIRA, Alda; SEQUEIRA, Deisilucy; SOUZA, Tatiane. “A Importância do ato de ler”: amorosidade, afetividade e diálogo como prática alfabetizadora.

Essas foram análises comprometidas com uma prática de liberdade, com criticidade, práxis, amorosidade e com a emancipação no contexto educacional, conceitos que devem permear todo o universo do conhecimento.

Diante das comemorações do Centenário de Paulo Freire, é importante ter o trabalho docente como um exercício de esperançar por uma educação democrática, inclusiva e equitativa. Identifica-se nos relatos das docentes uma prática diária de luta por justiça na educação pública sem perder a esperança, mas sem esperar, indo adiante. Vamos esperançar! 


\section{Referências bibliográficas}

BRANDÃO, C. R. A Educação como cultura. Memórias dos anos sessenta. Horizontes Antropológicos, Porto Alegre, ano 23, n.49, p.377-407, set/dez 2017.

BRANDÃO, C. R. O que é método Paulo Freire. São Paulo: Brasiliense, 2006.

BRANDÃO, C. R. O que é Método Paulo Freire. 38.ed. São Paulo: Brasiliense, 1981. Coleção Primeiros Passos.

BRASIL. Constituição da República Federativa do Brasil. Brasília: Senado Federal, 1988.

BRASIL. Lei 9.394, de 20 de dezembro de 1996. Lei de Diretrizes e Bases da Educação Nacional. Brasília, 1996.

BRASIL. Lei n. 13.005, de 25 de junho de 2014. Aprova o Plano Nacional de Educação e dá outras providências. Brasília, 2014.

BRASIL. Ministério da Educação. Diretrizes Curriculares Nacionais Gerais da Educação Básica. Brasília, 2013.

BRASIL. Ministério da Educação. Parâmetros curriculares nacionais: introdução aos parâmetros curriculares nacionais. Brasília, 1997.

BRASIL. Ministério da Educação. Base Nacional Comum Curricular (BNCC). Educação é a Base. Brasília, 2017.

DUARTE, C. S. Direito público subjetivo e políticas educacionais. São Paulo em Perspectiva. São Paulo, v.18, n.2, p.113-8, abr/jun, 2004.

FERREIRO, E.; TEBEROSKY, A. Psicogênese da Língua Escrita. Porto Alegre: Artes Médicas, 1985.

FREIRE, P. Cultura popular, educação popular: memória dos anos 60. Rio de Janeiro: Graal, 1983.

FREIRE, P. Pedagogia do Oprimido. Rio de Janeiro: Paz e Terra. 1967.

FREIRE, P. Pedagogia do Oprimido. 2.ed. Porto: Afrontamento, 1975.

FREIRE, P. Educação como Prática da Liberdade. 11.ed. Rio de Janeiro: Paz e Terra, 1980.

FREIRE, P. A Importância do Ato de Ler. São Paulo: Autores Associados, 1981.

FREIRE, P.; MACEDO, D. Alfabetização: leitura do mundo, leitura da palavra. Rio de Janeiro: Paz e Terra, 1990.

MORTATTI, M. R. L. História dos Métodos de Alfabetização no Brasil. Brasília: MEC/SEB, 2006. 
OLIVEIRA, Alda; SEQUEIRA, Deisilucy; SOUZA, Tatiane. “A Importância do ato de ler”: amorosidade, afetividade e diálogo como prática alfabetizadora.

Dignidade Re-Vista, v.7, n.12, jul 2021.

SOARES, M. Alfabetização e letramento. 7.ed. São Paulo: Contexto, 2020.

STRECK, D.; REDIN, E., ZITKOSKI, J. J. Dicionário Paulo Freire. Belo Horizonte: Autêntica, 2010. 